The Journal of Financial Research • Vol. X, No. 4 - Winter 1987

\title{
INTERVALLING EFFECTS IN HONG KONG STOCKS
}

\author{
John C. Larson* and Joel N. Morse **
}

\begin{abstract}
This paper investigates the intervalling-thinness effect in the Hong Kong stock market and compares the results with previous studies of United States and French data. The approach follows the three pass technique of Cohen, Hawawini, Maier, Schwartz, and Whitcomb. Various functional forms of an intervalling bias decay function are analyzed, both in the aggregate and for individual stocks. Careful modeling of the flattening of the beta profile at a finite interval value leads to robust estimated asymptotic betas.
\end{abstract}

\section{Introduction}

Recent research has established that ordinary least squares beta estimates are systematically sensitive to the length of the time interval used to define the rates of return (see Cohen, Hawawini, Maier, Schwartz, and Whitcomb (CHMSW), 1980, 1983a, 1983b; Dimson, 1979; Fowler and Rorke, 1983; Fowler, Rorke, and Jog, 1979, 1980; McInish and Wood, 1985a, 1985b, 1986; and Scholes and Williams, 1977). Especially for thin, infrequently traded securities, monthly data generate quite different beta estimates from daily data. CHMSW argue that such intervalling effects are caused by the institutional features of the trading environment as well as by the existence of transactions costs. The resulting frictions delay the adjustment of a security price to new information. CHMSW introduce a three pass regression technique for adjusting daily estimates toward unbiased values that would be found if extremely long time intervals could be used. Such adjusted values, referred to as asymptotic betas, may be useful in market studies. For example, Jorion and Schwartz (1986) find that intervalling corrections are crucial for their conclusions about market segmentation. Similarly, Grammatikos (1986) shows that intervalling bias affects estimation of optimum hedge ratios for foreign currency futures.

Most work has been done on the intervalling effect in United States stock markets, but Fung, Schwartz, and Whitcomb (FSW) (1985) expand the investigation by using the CHMSW three pass technique on data from the Paris Bourse. A unique focus of the present paper is the application of the same technique to stocks traded in Hong Kong. Because Pogue and Solnik (1974) find that intervalling effects across seven European markets are greater than in the United States, and tend to be larger the smaller the market, it is expected that Hong Kong stocks will exhibit nontrivial amounts of intervalling. Beyond showing the extent of the expected intervalling effect within Hong Kong stocks, this study examines the robustness of the asymptotic betas to several variations in the three pass technique's implementation.

*Loyola College in Maryland, Baltimore.

**University of Baltimore.

The authors thank the editor, the anonymous referees, and Thomas H. McInish for valuable comments. Detailed information omitted for brevity is available from the authors. 
In the first pass of the CHMSW technique, the market model is estimated by ordinary least squares over various return intervals. It is possible to assess robustness of this pass using all interval values from one to 30 days as in FSW, or to follow CHMSW in using selected interval values that help control sampling errors. This issue is discussed in Section III. Second pass regressions relate the first pass betas for each stock to the measurement intervals using an intervalling bias decay function to obtain an estimated asymptotic beta that is purged of intervalling bias. To differentiate firms according to trading friction, third pass regressions relate a second pass measure of the total intervalling effect in one day betas to firm-specific variables. The point is to determine an easily calculated inferred asymptotic beta that equals the more difficult to calculate second pass estimated asymptotic beta. If this is possible, bias-correcting adjustments to one day betas are easier. If this is not possible, the CHMSW three pass technique provides the requisite information via the estimated asymptotic betas that require pass-two calculations. Because this much calculation is undesirable, a method is sought to prescribe a minimum interval that yields pass-one betas that correspond strongly to the estimated asymptotic betas. A third pass is also attempted to obtain inferred asymptotic intervals.

Alternative specifications of the second pass intervalling bias decay functions are explored in this paper, a research theme initiated by FSW. In particular, the focus is on whether the estimated asymptotic betas might be overstated if intervalling bias is dissipated at modest interval values rather than asymptotically. That is, functional form research may reveal the apparent duration of intervalling effects. This new idea is fundamental to the Hong Kong findings. A standard full information maximum likelihood criterion is used for each of the second pass simultaneous equation system estimates. Pass three is conducted as in CHMSW and FSW to obtain inferred asymptotic betas and to examine the prediction of the apparent duration of intervalling effects.

\section{Technique Selection Rationale}

Selection of the CHMSW three pass technique is based on the work of FSW and the technique comparisons by McInish and Wood (1986). McInish and Wood compare the CHMSW inferred asymptotic beta with alternative correction techniques developed by Scholes and Williams (1977), Dimson (1979), and Fowler, Rorke, and Jog $(1979,1980)$. The Scholes and Williams technique applies the market model separately to market returns that lead, lag, and coincide with the individual stock returns, and calculates an adjusted beta for each stock as a weighted average of these three values that depends upon the serial correlation exhibited in the market index. Fowler and Rorke (1983) and CHMSW (1983b) generalize this technique to account for stocks with consecutive nontrading days. However, FSW and McInish and Wood show that these adjusted betas are incompletely purged of intervalling effects. Dimson's technique uses multiple regression to fit the stock returns to leading, coincident, and lagging market returns and adds the coefficients to obtain an adjusted beta. Fowler and Rorke show that Dimson's multiple regression coefficients should be combined as a weighted sum to achieve proper beta adjustment, but McInish and Wood show this also suffers from an incomplete removal of the intervalling effect. As for the 
CHMSW inferred asymptotic betas, McInish and Wood show a tendency to correct too much, while other methods undercorrect. Even though they apply the non-Lachenbruch inferred variant that CHMSW indicate is slightly biased, the magnitude of the overcorrection is disturbing. Their suggestion that additional specification research could improve the technique is followed.

\section{Methodology}

\section{Pass one}

Ordinary least squares is used in the first pass to estimate the market model beta for each of 40 Hong Kong stocks. This is done for 16 return measurement intervals. The model in CHMSW notation is

$$
r_{j L t}={ }_{1} a_{j L}+{ }_{1} b_{j L} r_{M L t}+{ }_{1} e_{j L t} \text { for } t=1,2, \ldots, T / L
$$

where $r_{j L t}$ is the continuously compounded holding period return for the $j^{\text {th }}$ security during the $t^{\text {th }}$ interval of length $L$ days and $r_{M L t}$ is the equivalent holding period return of the Hang Seng Index (see Section IV). Natural logarithms of nonoverlapping $L$ day price relatives are used to determine these returns, as in FSW. Lower prescripts identify terms related to the first, second, or third passes.

The sample size of $T=960$ daily returns is the same as in CHMSW. Interval values used are $L=1,2,3,4,5,6,8,10,12,15,16,20,24,30,32$, and 40 . This set of $L$ values allows the sample to be partitioned so that the complete base of daily sampling error information is maintained as multiday intervals are considered. Theoretically, other $L$ values inject unnecessary sampling error variations into the pass-one betas by using fewer than 960 daily observations; e.g., with $L=7$ only 959 days would be used and with $L=39$ only 936 . Because sample sizes that are integer multiples of $60=1 \times$ $3 \times 4 \times 5$, such as 960 , enable the first five days to be covered and otherwise provide a liberal number of admissible larger $L$ values, there is little need to use incomplete sample partitioning as with $L=7$ and $L=39$.

\section{Pass two}

Pass two is conducted to quantify and determine the sign of the intervalling effect for each security. Estimated first pass betas for all securities are fitted to an intervalling bias decay function, $F(L)$, as a 40 equation, 16 observation per equation, seemingly unrelated regression (SUR) model

$$
{ }_{1} \hat{b}_{j L}={ }_{2} a_{j}+{ }_{2} b_{j} F(L)+{ }_{2} e_{j L}
$$

where

$$
\begin{aligned}
& j=1,2, \ldots, 40, \text { and } \\
& L=1,2,3,4,5,6,8,10,12,15,16,20,24,30,32,40 .
\end{aligned}
$$


Following CHMSW, the intervalling bias decay function $F(L)$ is restricted so that $F(1)=1$ with monotonic decay toward zero exhibited as $L$ increases without bound. By these restrictions, ${ }_{2} a_{j}$ is the limiting value of the market model beta for stock $j$ when $L$ increases without bound and ${ }_{2} b_{j}$ is the magnitude of the intervalling effect at $L=1$. The estimated asymptotic beta for stock $j,{ }_{2} \hat{a}_{j}$, is an unbiased estimate of ${ }_{2} a_{j}$ within the CHMSW theory. With $F(L)=g(L) f(L)$, four $f(L)$ forms are used: the CHMSW power function $f(L)=L^{-n}$; the logarithmic FSW selection $f(L)=\ln \left(1+L^{-n}\right) / \ln (2)$; the FSW exponential $f(L)=e^{x}$ where $x=1-L^{n}$; and a two parameter alternative $f(L)=a^{x}$ where $a>1$. Parameter $n$ must be positive for all four functions. If $1<a<$ $e$ and if the four $f(L)$ functions are equated at $L=40$, for example, then a plotting exercise will reveal they are ranked from most to least curvaceous. If $a>e$, then the order of the last two is reversed.

The second pass may reveal a lower limit interval value where the intervalling effect is no longer present. Many stocks' pass-one betas plotted with respect to $L$ seem to show a rapid stabilization in value in the range of interval values between 20 and 40 days. Thus, the form $F(L)=g(L) f(L)$ is used where $g(L)$ is a kinked, piece-wise linear function (consistent with the CHMSW monotonicity requirement) that models an accentuated transition from a pronounced curvature pattern of bias decay at low $L$ values to a plateau pattern. Specifically, $g(L)=\operatorname{MAX}\left[\left(L^{*}-L\right) /\left(L^{*}-1\right), k\right]$ where $L^{*}>1$ and $k<1$ are non-negative parameters to be estimated. If $k$ equals zero (as indicated in our estimates), then the estimate of $L^{*}$ suggests a lower limit interval value, which might be used with the market model in lieu of use of pass-three inferred asymptotic betas. If ${ }_{2} b_{j}$ is nonzero and $k$ is nontrivially positive, the implication is that the first pass beta estimate retains intervalling bias unless $L$ is incredibly large. Increasing $L^{*}$ without bound (with $k=0$ ) implies $F(L)=f(L)$. This specification generalizes the CHMSW and FSW intervalling bias decay functions.

Maximum likelihood estimates for this SUR model are obtained by minimizing the determinant of the estimated variance-covariance matrix of the 40 stocks' disturbances, which is assumed to be diagonal. Larson (1986) demonstrates in a consumer demand context that likelihood ratio tests under this assumption are typically the same as when using a nondiagonal disturbance variance-covariance matrix.

\section{Pass three}

The third pass regresses the ${ }_{2} \hat{b}_{j}$ for the 40 securities against one or more firm specific variables (or proxy variables) that are hypothesized to correlate highly with the market frictions that cause intervalling bias. CHMSW and FSW use the natural logarithm of the market capitalization of the various equities at the mid-point of the sample period, $\ln V_{j}$, for their proxy. CHMSW also report less successful experiments with alternative proxies such as $V_{j}$, number of shares traded, and the logarithm of number of shares traded. The CHMSW third pass regression for stock $k$ is of the form

$$
{ }_{2} \hat{b}_{j}={ }_{3} a_{k}+{ }_{3} b_{k} \ln V_{j}+{ }_{3} e_{j} \text { for } j=1, \ldots, k-1, k+1, \ldots, 40
$$

with the inferred asymptotic beta computed as $b_{k}^{*}={ }_{1} \hat{b}_{k l}-\left({ }_{3} \hat{a}_{k}+{ }_{3} \hat{b}_{k} \ln V_{k}\right)$. The best empirical results occur with end of sample $V_{j}$. These values rather than those at mid- 
sample coincide more closely with those practitioners will use in applying the inferred corrections technique.

\section{Data}

Hong Kong is one of the most volatile stock markets in the world. The Hang Seng Index, the most prominent of local indices, reached 1775 in 1972-73 and collapsed to 150 in 1974. It rose to 1810 in July 1981, fell back to 676 in December 1982, and recovered to 1000 in early 1983 . The market crashed again at this point as Great Britain and the People's Republic of China began earnest negotiation concerning the governance of Hong Kong after 1997 when most of the original Crown leases expire.

Approximately 265 companies were listed on the four Hong Kong stock exchanges during the sample period of 961 trading days (excluding holidays and weekends) ending May 17, 1985. The sample is restricted to the 45 firms whose financial statements are available in Moody's International Manual. Monday through Friday closing prices are obtained from Computact (H.K.), Ltd. These data are checked in the Wall Street Journal, the Far Eastern Economic Review, and the South China Morning Post. Several cases of unusual daily price movement that appear to be typographical errors are resolved, and random checks in these references confirm the quality of the primary data record. As in FSW, five of the 45 stocks are exempt from further analysis because they show occasional one day returns exceeding 35 percent. Of the 40 firms remaining, one stock has two nontrading days, which for simplicity are set equal to the previous day's closing price.

That the sample shows only two nontrading days is unusual. Scholes and Williams find that nontrading days represent 2 percent of their sample, whereas Dimson's 20year study of United Kingdom data indicates that over half of the sample has this thinness characteristic. In short, samples differ widely and the Hong Kong stocks do not, by this measure, exhibit extremely thin trading. McInish and Wood use transactions data and discard nontrading days in the same manner as a holiday. Fowler, Rorke, and Jog (1980) and Jog and Riding (1986) replace zeroes with simulated data. Having few nontrading days is consistent with the sample's composition of regularly traded firms ranging in value from HK\$ 37.8 million to $\mathrm{HK} \$ 23.8$ billion. The average price of shares is only HK\$ 6.32 (less than US\$1.00). Share volume is high in unit terms. On a day near the midpoint of the sample, the average volume for these stocks is nearly 366,500 shares per day. Spot checks on other nearby days show a minimum volume of 100 for one stock and a maximum of 7,456,000 shares traded per day for another.

Hong Kong is a low friction trading environment for fiscal, legal, and cultural reasons. Individuals do not pay income taxes on either dividends or capital gains. Institutional Investor (1984) describes Hong Kong exchanges as "among the more gossipy and fast moving in the world." The Economist (1986) echoes this, stating that "in worldly Hong Kong, charges of insider trading attract a cynical 'so what'." Despite this climate, or perhaps because of it, the Hong Kong market is the largest and most effective Asian locus for stock trading outside of the Japanese markets.

During the sample period, Hong Kong's four stock exchanges were the Hong Kong, the Far East, the Kam Ngan, and the Kowloon. Each of the sample stocks is listed on 
at least three of the four exchanges. Volume figures by exchange for these days are 20 percent for the Hong Kong exchange, 40 percent for the Far East exchange, 40 percent for the Kam Ngan exchange, and nearly 0 percent for the Kowloon exchange. These estimates of daily volume and its distribution over the four exchanges are approximately the same for entire year of 1982. Since the Far East exchange is the largest and most liquid, its closing prices are used. Administrative difficulties and redundant trading capacity led to the 1981 Stock Exchanges Unification Ordinance directing a merger of the four exchanges (completed in 1986). The exchange is open between 10:00 A.M. and 12:30 P.M. and from 2:30 to 3:30 P.M. Monday through Friday. Unlike Japan, there are no Saturday trading sessions. Trading occurs directly between brokers continuously without the intervention of a specialist. At various trading posts, buy and sell orders are matched through open outcry, with settlement one day after the trade. Trades are normally in standardized lot sizes known as "Board Lots," which are determined by Exchange Councils. There is no forward market for individual stocks such as described in FSW, although trading of listed futures contracts on the Hang Seng Index began in 1986.

The Hang Seng Index is used for computing market returns. This index is calculated as $\mathbf{1 0 0}$ times the current total market value of its 33 constituent stocks, divided by their July 31, 1964 market value. Allowances are made for capital changes in the component securities by the Hang Seng Bank, administrator of the index. During the sample period, six stocks are deleted and six are added. Typically the index represents between 60 percent and 70 percent of total market capitalization and 60 percent to 80 percent of daily trading. At the end of the sample period, 17 of the 40 stocks in the sample are elements of the index, accounting for over 60 percent of its value. The five largest stocks represent 40 percent of the index. All the stocks are included in Moody's International Manual, 10 are covered in Moody's Dividend Record, 25 are quoted in the Far East Economic Review, and 12 are traded in the United States as American Depositary Receipts.

\section{Empirical Results}

\section{Hong Kong results using CHMSW technique}

The first stage results presented in Table 1 agree strongly with those of CHMSW and FSW. Average betas rise and their $t$-statistics drop with increases in the differencing interval $L$. Summary statistics on the two asymptotic betas are presented in the right two columns for comparison purposes.

The second stage estimates equation system (2). Theory does not provide an unambiguous selection criterion for the intervalling effect function $F(L)$. All four alternative specifications are found to provide approximately the same results and only slight differences in the estimated variance product criterion. The best fit specification is the CHMSW variant with $\hat{n}=.195$. To establish the estimate of $n$, the minimum variance product criterion is determined by gridding on successive $n$ values of .005 difference. This also reveals that the likelihood surface has considerable curvature so that the estimate of $n$ is well determined. Each of the four $F(L)$ estimates leads to the same $\hat{L}^{*}=30$ and $\hat{k}=0$ values. Information about first pass beta sampling error is used to 


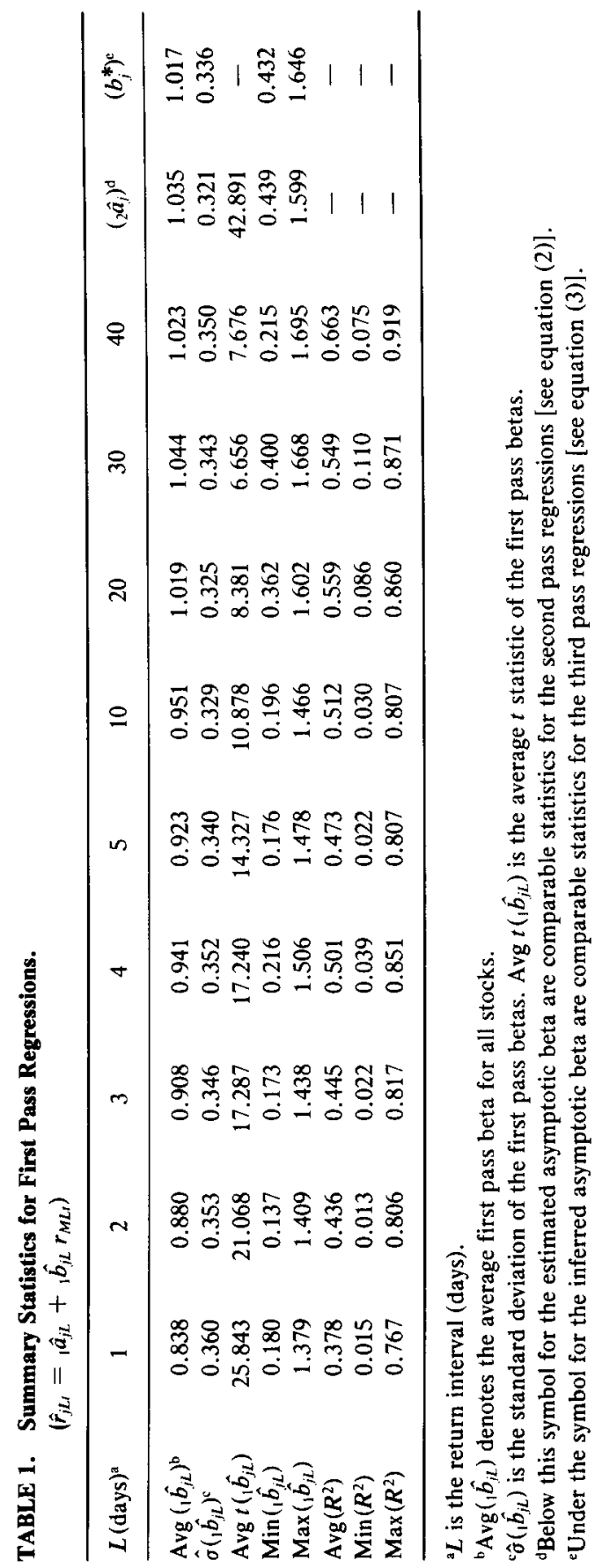


correct for heteroskedasticity. Specifically, all variables are divided by the pass one beta standard errors. The estimated asymptotic betas are the intercept terms, ${ }_{2} \hat{a}_{j}$.

When the pass-two regressions are run using only the four $f(L)$ functions with $g(L)$ set equal to one, the maximum likelihood estimate of the exponent is negative. Only if interval values beyond 20 days are discarded is there a positive exponent. These results suggest the need for use of a $g(L)$ function with some data sets. Examination of $L^{*}$ is carried further in the next subsection.

As in CHMSW's study of U.S. stocks, most of the ${ }_{2} \hat{b}_{j}$ are negative; beta rises as $L$ increases for most stocks in the sample. Four of the securities show a positive significant relationship between beta and the interval length. Their market capitalizations are among the largest in the sample. This is similar to the CHMSW finding on the NYSE and is completely consistent with their intervalling theory. These four stocks trade on several other foreign stock exchanges, as well as in American Depositary Receipt form. In Grieg, Hildeburn, and Lim (1985), three of these appear in a list of several hundred stocks that trade on a global basis; two are traded in London. Price adjustment delays may be affected by arbitrage across these markets, as well as by the more intense scrutiny received by world-traded equities.

Pass three is conducted to establish inferred asymptotic betas. Following CHMSW, the natural logarithm of each firm's market capitalization $V_{j}$ is used as a proxy for trading delays and consequent price adjustment delays. Specifically, the regression model for stock $k$ is (3), shown earlier. Excluding observation $k$ provides the Lachenbruch hold-out sample that CHMSW advocate to avoid unnecessary estimator bias.

Results are similar to those of CHMSW. The $R^{2}$ statistics are less than in CHMSW and more than in FSW. In contrast to the FSW finding, when statistically insignificant stocks of pass two are excluded from the overall pass-three regression, the $R^{2}$ value drops to .238 from .299 . Six of the 10 deleted stocks come from the largest third of the sample. Similarly, 8 of the 10 firms with insignificant pass-two $t$-statistics are in the larger half of the CHMSW sample. But in FSW, the 23 deleted companies are apparently close to the sample average. Pass-three results are strongly sample dependent, even when modified as above. This renders findings highly variable across markets.

\section{Hong Kong results using a modified technique}

Conceptually, it is as informative to consider the interval value at which beta bias becomes negligible as it is to compare one day and asymptotic betas. This duration dimension of the intervalling effect may be especially useful if it clarifies the set of $L$ values for pass two. It also leads to a better pass-three approach if duration is more easily proxied than magnitude.

First pass betas plotted against $L$ often suggest a plateau in the 20 to 40 day range of interval values. If a bias decay function is fitted only to intervals up to 20 days, without regard for the possibility of abrupt flattening of the pattern at a slightly larger $L$ value, the resulting estimated asymptotic beta could be biased. Because such bias would be carried into the inferred asymptotic beta and because CHMSW determine their bias decay function only on intervals up to 20 days, a possible source is suggested for the bias detected by McInish and Wood (1986). This proposition is substantiated for 
Hong Kong data. That is, using $F(L)=f(L)=L^{-\mathrm{n}}$ leads to $\hat{n}=0.160$ and greatly changed ${ }_{2} \hat{a}_{j}$ and $b_{j}^{*}$ values. With this finding, concern shifts to whether the second stage results correspond strongly to what would be found by fitting an individualized bias decay function to each stock. The individualized estimates show this correspondence. Such robustness indicates that pass two should be conducted on interval values that extend appreciably beyond 20 days. This appears to be vastly more important than allowing for stock specific $L_{j}^{*}$ values.

Hong Kong data require the $g(L)$ modification of the bias decay function to obtain positive $\hat{n}$ values when intervals beyond 20 days are considered. A common $\hat{L}^{*}$ value works as well as individualized values. Nonetheless, it is interesting to consider whether knowing the individual stocks' plateau points would be useful. By using the pass one betas corresponding to the estimated asymptotic intervals $\hat{L}_{j}^{*}$ as inferred asymptotic betas the correlation between the estimated and inferred asymptotic betas rises from 0.845 to 0.958 . With this improvement potential, the final issue becomes predictability of the $\hat{L}_{j}^{*}$ in the sense of a pass three regression strategy. But attempts to predict $\hat{L}_{j}^{*}$ are discouraging. Virtually no relation exists between size of firm and intervalling duration.

Nonsynchronous balance sheet dates, changing relative market capitalizations, and the fact that the floating supply of shares is often much lower than the number of shares outstanding all confound international comparisons of pass three results. Data availability and documentation, as well as institutional differences, make it difficult to match samples on firm specific variables. Considering this strong sample dependency of pass three and the minimal extra-sample information required by pass two, increased emphasis on estimated asymptotic betas is suggested.

\section{Conclusion}

This paper investigates the intervalling-thinness effect in the Hong Kong stock market, using and extending the three pass technique of CHMSW. Literature on the intervalling effect is reviewed, reasons for selecting the CHMSW technique are discussed, and relevant institutional aspects of the Hong Kong market are detailed. Empirical results are analyzed and compared with those of CHMSW and FSW in the United States and French markets.

Four functional forms for the pass two intervalling bias decay function are analyzed. Of the four, an exponential form related to the one used originally by CHMSW is found superior by a small margin. This similarity over functional forms is a result of use of a plateau accentuation modification on each of the functions.

The plateau accentuation modification is necessary to examine intervals longer than 20 days in Hong Kong and introduces another way of viewing the intervalling effect. Instead of looking at the magnitude of the change in beta as the interval $L$ is increased without bound, the method suggests a finite lower limit interval $L^{*}$ where the intervalling effect is dissipated and beta plateaus. Pass two results using a common $L^{*}$ value versus a unique $L^{*}$ value for each stock indicate little difference in estimated asymptotic betas. This robustness is encouraging because the complexity of individualized bias decay functions makes computing pass-two calculations considerably more difficult. 
Pass three results are slightly better than those FSW found with French stocks, but well below CHMSW findings for the NYSE. It appears that no simple proxy for thin trading is likely to suffice for all markets. To facilitate cross-market studies and the search for successful pass three proxies, some implementable scheme for controlling for firm characteristics will be needed. At present, handling of beta bias for short return intervals is best approached with pass two estimated asymptotic betas.

\section{References}

Cohen, K. J., Hawawini, G. A., Maier, S. F., Schwartz, R. A., and Whitcomb, D. K. (1980) "Implications of Microstructure Theory for Empirical Research on Stock Price Behaviors." Journal of Finance, 35 (May), pp. 249-257.

Cohen, K. J., Hawawini, G. A., Maier, S. F., Schwartz, R. A., and Whitcomb, D. K. (1983a) "Estimating and Adjusting for the Intervalling-Effect Bias in Beta." Management Science, 29 (January), pp. 135148.

Cohen, K. J., Hawawini, G. A., Maier, S. F., Schwartz, R. A., and Whitcomb, D. K. (1983b) "Friction in the Trading Process and the Estimation of Systematic Risk." Journal of Financial Economics, 12, pp. 263-278.

Dimson, E. (1979) "Risk Measurement When Shares Are Subject to Infrequent Trading." Journal of Financial Economics, 7 (June), pp. 197-226.

Fowler, D. J. and Rorke, C. H. (1983) "Risk Measurement When Shares Are Subject to Infrequent Trading: Comment." Journal of Financial Economics, 12, pp. 279-283.

Fowler, D. J., Rorke, C. H., and Jog, V. M. (1979) "Heteroscedasticity, R2 and Thin Trading on the Toronto Stock Exchange." Journal of Finance, 34 (December), pp. 1201-1210.

Fowler, D. J., Rorke, C. H., and Jog, V. M. (1980) "Thin Trading and Beta Estimation Problems on the Toronto Stock Exchange." Journal of Business Administration, 12 (Fall), pp. 77-90.

Fung, W. K. H., Schwartz, R. A., and Whitcomb, D. K. (1985) "Adjusting for the Intervalling Effect Bias in Beta." Journal of Banking and Finance, 9 (September), pp. 443-460.

Grammatikos, T. (1986) "Intervalling Effects and the Hedging Performance of Foreign Currency Futures.” Financial Review, 21 (February), pp. 21-36.

Greig, K., Hildeburn, C., and Lim, Q. P. (1985) "The Surge in International Equities." Euromoney, (May), pp. 121-149.

Institutional Investor. (1984) "Hong Kong." (May), pp. 11-13.

Jog, V. R. and Riding, A. L. (1986) "Some Canadian Findings Regarding Infrequent Trading and Instability in the Single Factor Market Model." Journal of Business Finance and Accounting, 13, pp. 125-135.

Jorion, P. and Schwartz, E. (1986) "Integration vs. Segmentation in the Canadian Stock Market." Journal of Finance, 41 (July), 3, pp. 603-614.

Larson, J. C. (1986) “An Elegant Price Flexibility Modification to the Widely Used Linear Expenditure System." Economics Letters, 20, pp. 197-200.

McInish, T. H. and Wood, R. A. (1985a) "A New Approach to Controlling for Thin Trading." Journal of Financial Research, 8 (Spring), 1, pp. 69-75.

McInish, T. H. and Wood, R. A. (1985b) "Assessing the Intervalling-Effect Bias in Risk Estimation." Working Paper, Department of Finance, Pennsylvania State University, University Park.

McInish, T. H. and Wood, R. A. (1986) "Adjusting for Beta Bias; An Assessment of Alternative Techniques." Journal of Finance, 41 (March), 1, pp. 277-286.

Pogue, G. A. and Solnik, B. H. (1974) "The Market Model Applied to European Common Stocks: Some Empirical Results." Journal of Financial and Quantitative Analysis, 9 (December), pp. 917-944.

Scholes, M. and Williams, J. (1977) "Estimating Betas from Nonsynchronous Data." Journal of Financial Economics, 5, pp. 309-327.

The Economist. (1986) "Insider Trading." (May 31), p. 87. 
Copyright of Journal of Financial Research is the property of Wiley-Blackwell and its content may not be copied or emailed to multiple sites or posted to a listserv without the copyright holder's express written permission. However, users may print, download, or email articles for individual use. 